\title{
Primary Ciliary Dyskinesia
}

\author{
Fatma Çiftçi MD, Pergin Atilla MD PhD, Sevda Müftüoğlu MD PhD, and Demet Karnak MD
}

\section{Introduction}

Primary ciliary dyskinesia (PCD) is a rare genetic condition that affects the ciliary function of the respiratory tract, sperm tail, cilia of the embryonic node, and fallopian tube. The condition is characterized by impaired ciliary action, leading to recurrent lower-respiratory-tract infections, bronchiectasis, rhino-sinusitis, otitis media, impaired fertility in women, and infertility in men. ${ }^{1}$

Early diagnosis is important to prevent disease progression. ${ }^{2}$ Examination of nasal or bronchial biopsy specimens by electron microscopy is the definitive diagnostic test.

We present a 36-year-old woman with a history of recurrent lower-respiratory-tract infections and bronchiectasis. She was diagnosed with PCD, based on clinical presentation and electron microscopy of bronchial biopsy.

\section{Case Report}

A 36-year-old female patient was referred to our clinic for evaluation of her dyspnea, fever, and productive cough with purulent sputum production for a week. She had a history of recurrent episodes of lower-respiratory-tract infections since childhood. She had been hospitalized 3 times, and treated with antibiotics, expectorants, and bronchodilators in the last year. There was no history suggestive of recurrent rhino-sinusitis. She had undergone right middle lobectomy, with the diagnosis of bronchiectasis, 11 years prior to the referral. She was working as an English teacher in a junior high school. She was a nonsmoker. Her parents were relatives with each other, and her sister also had a diagnosis of bronchiectasis. She had

Drs Çiftçi and Karnak are affiliated with the Department of Chest Disease, Ankara University School of Medicine, Ankara, Turkey. Drs Atilla and Müftüoğlu are affiliated with the Department of Histology and Embryology, Hacettepe University School of Medicine, Ankara, Turkey.

The authors have disclosed no conflicts of interest.

Correspondence: Demet Karnak MD, Department of Chest Disease, Ankara University School of Medicine, 06100 Cebeci, Ankara, Turkey. E-mail: demet.karnak@gmail.com.

DOI: $10.4187 /$ respcare.02241 twins via in vitro fertilization, 12 years after getting married.

On physical examination her temperature was $39^{\circ} \mathrm{C}$, blood pressure was $130 / 75 \mathrm{~mm} \mathrm{Hg}$, heart rate was 110 beat/ min (rhythmic), breathing frequency was 24 breaths/min, and resting oxygen saturation $94 \%$ on room air. Bilateral wheezing and inspiratory coarse crackles were audible. Laboratory findings included: white blood cell count 13,700 cells/mL (77.6\% neutrophils), hemoglobin $13.4 \mathrm{~g} /$ $\mathrm{dL}$, platelets 196,000 cells $/ \mathrm{mL}$, C-reactive protein $62.9 \mathrm{mg} / \mathrm{L}$, and erythrocyte sedimentation rate $56 \mathrm{~mm} / \mathrm{h}$.

Pulmonary function tests found FVC $2.16 \mathrm{~L}$ (71\% of predicted), $\mathrm{FEV}_{1} 1.60 \mathrm{~L}$ ( $61 \%$ of predicted), and $\mathrm{FEV}_{1} /$ FVC $74.1 \%$ (normal value $86.2 \%$ ), revealing mild restriction and obstruction.

Arterial blood gas analyses revealed mild hypoxemia $\left(\mathrm{P}_{\mathrm{aO}_{2}} 71 \mathrm{~mm} \mathrm{Hg}\right)$, oxygen saturation $94 \%$, and normal $\mathrm{P}_{\mathrm{aCO}_{2}}$ (42 mm Hg).

Her chest $\mathrm{x}$-ray revealed bilateral bronchiectasis, with lower lobe predominance, and linear reticular opacities, more prominent at the lung bases (Fig. 1). Electrocardiogram showed $\mathrm{P}$ pulmonale (indicating right atrial dilatation) and $\mathrm{T}$ wave flattening in precordial derivations. Highresolution computed tomography confirmed extensive bilateral bronchiectasis of the lower lobes (Fig. 2). A saccharin test demonstrated a delayed mucociliary transport time of $65 \mathrm{~min}$.

Fiberoptic bronchoscopy showed widespread viscous sputum and numerous mucosal crypts. Bronchoalveolar lavage (BAL) was performed with the fiberoptic bronchoscope, in a wedge position within the affected lower lobe medial segment: $200 \mathrm{~mL}$ of sterile, room-temperature, $0.9 \%$ saline was instilled into the alveolar space in $50-\mathrm{mL}$ aliquots, and gently removed, and $120 \mathrm{~mL}$ of BAL fluid was retrieved. The BAL fluid had $127 \times 10^{6}$ cells $/ \mathrm{mL}$ : $87 \%$ alveolar macrophages, $1.1 \%$ lymphocytes, $10 \%$ neutrophils, and $0.2 \%$ eosinophils. The CD4/CD8 ratio of lymphocytes was 0.6. A BAL specimen was sent to the microbiology laboratory for fungal, anaerobic and aerobic microorganisms, and acid-fast bacilli studies. Pseudomonas aeruginosa was grown on culture.

The middle lobe segments were not seen, and a suture material was seen at the entry of the middle lobe. Five 


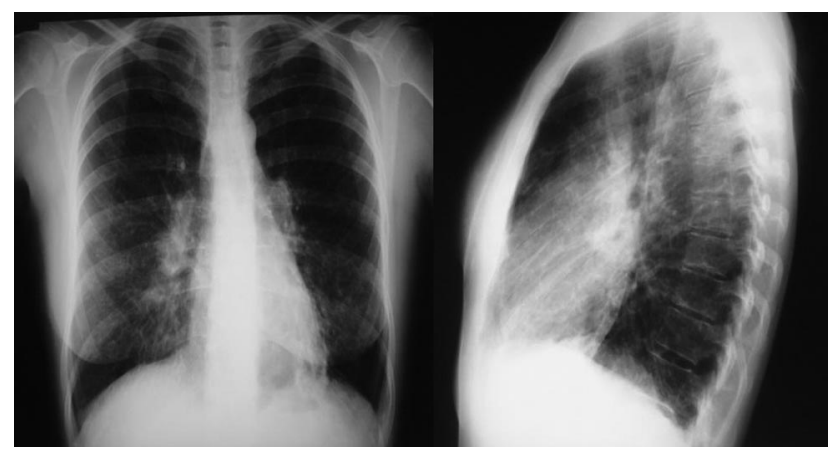

Fig. 1. Chest x-ray shows linear reticular opacities, more prominent at the lung bases.

punch biopsies from the carina of the upper lobe were obtained and put into sterile $2.5 \%$ glutaraldehyde fixative solution in phosphate buffer and processed according to the routine electron microscopy technique ${ }^{3}$ (Figs. 3 and 4). The outer dynein arms were deficient, and some of the central microtubules were single. PCD was the diagnosis.

The patient was managed with intravenous antibiotics, mucolytics, and bronchodilators. She improved with inhaled colistin for 6 months, with remission of fever and reduction of sputum production.

\section{Discussion}

PCD is a phenotypically and genetically heterogeneous group of conditions associated with abnormal ciliary structure and function. It has an autosomal-recessive inheri- tance pattern, although rarely other modes of inheritance, such as X-linked, have been described. The prevalence is estimated at approximately 1 in 20,000-60,000 individuals. ${ }^{1,2}$ The prevalence of PCD may be high in regions where consanguineous marriage is common. ${ }^{4}$ Clinical manifestations include recurrent respiratory-tract infections, chronic sinusitis, rhinitis, otitis media, and infertility. ${ }^{5}$ Isolated lower-respiratory infections are quite rare $(0.4 \%)$. Sinopulmonary infections are generally observed (76.9\%). Our patient had recurrent lower-respiratory-tract infections and no history of rhino-sinusitis. Radiologic and clinical assessment is important in the diagnosis of PCD. Common findings on chest x-ray and CT are lung hyperinflation, bronchial wall thickening, segmental atelectasis, and bronchiectasis. ${ }^{6}$

The diagnosis of PCD may be delayed or missed because the findings are nonspecific and seen in other chronic respiratory diseases such as refractory asthma, atypical cystic fibrosis, pulmonary sequestration, yellow nail syndrome, and middle-lobe/lingula syndrome. ${ }^{7}$

Situs inversus is a useful finding when PCD is suspected; our case did not have situs inversus, but that does not exclude the diagnosis, since it is present only in approximately $50 \%$ of patients with PCD. ${ }^{8}$

Various tests are used in PCD diagnosis. Exhaled nitric oxide may be used as a screening test, with levels of nitric oxide being characteristically low. The saccharin test is used to evaluate mucociliary function. Saccharin transport time from inferior turbinate to oropharynx will be $>60 \mathrm{~min}$ in patients with PCD. Ciliated epithelial cells obtained

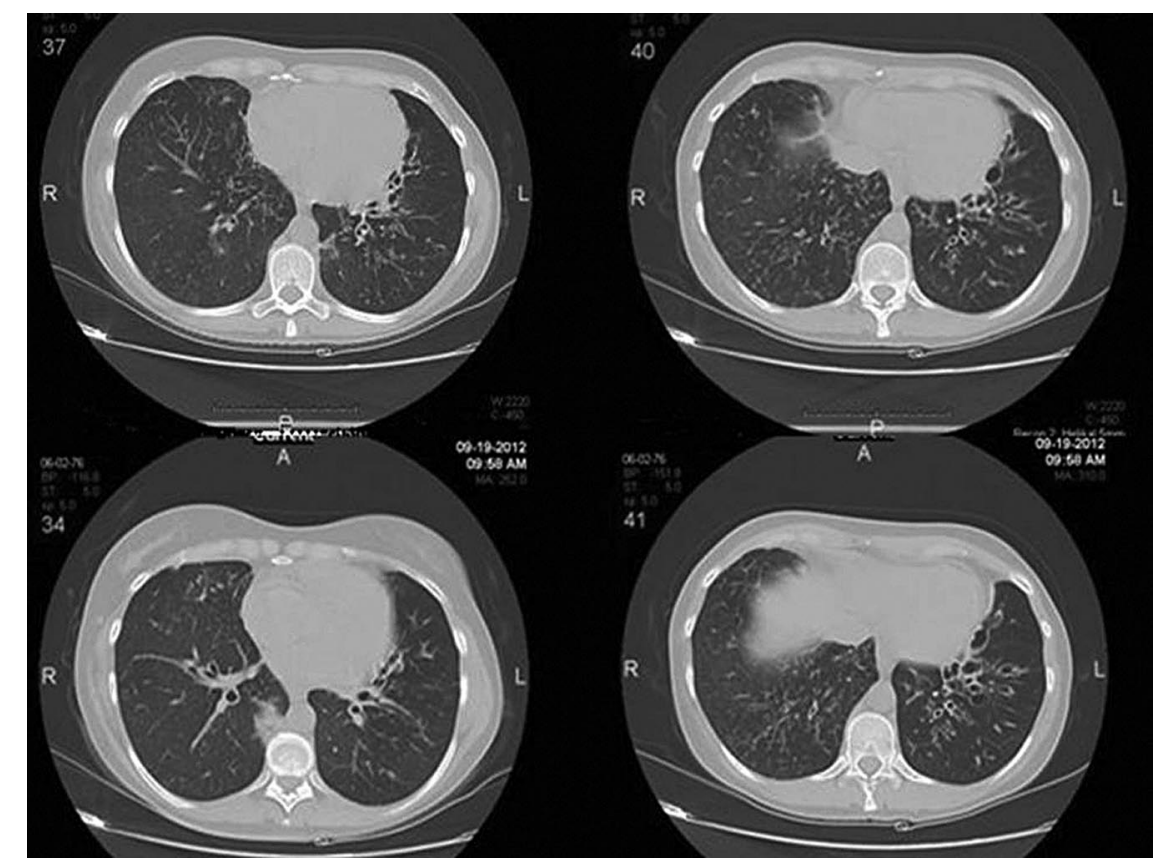

Fig. 2. Computed tomogram shows bilateral cystic bronchiectasis. 

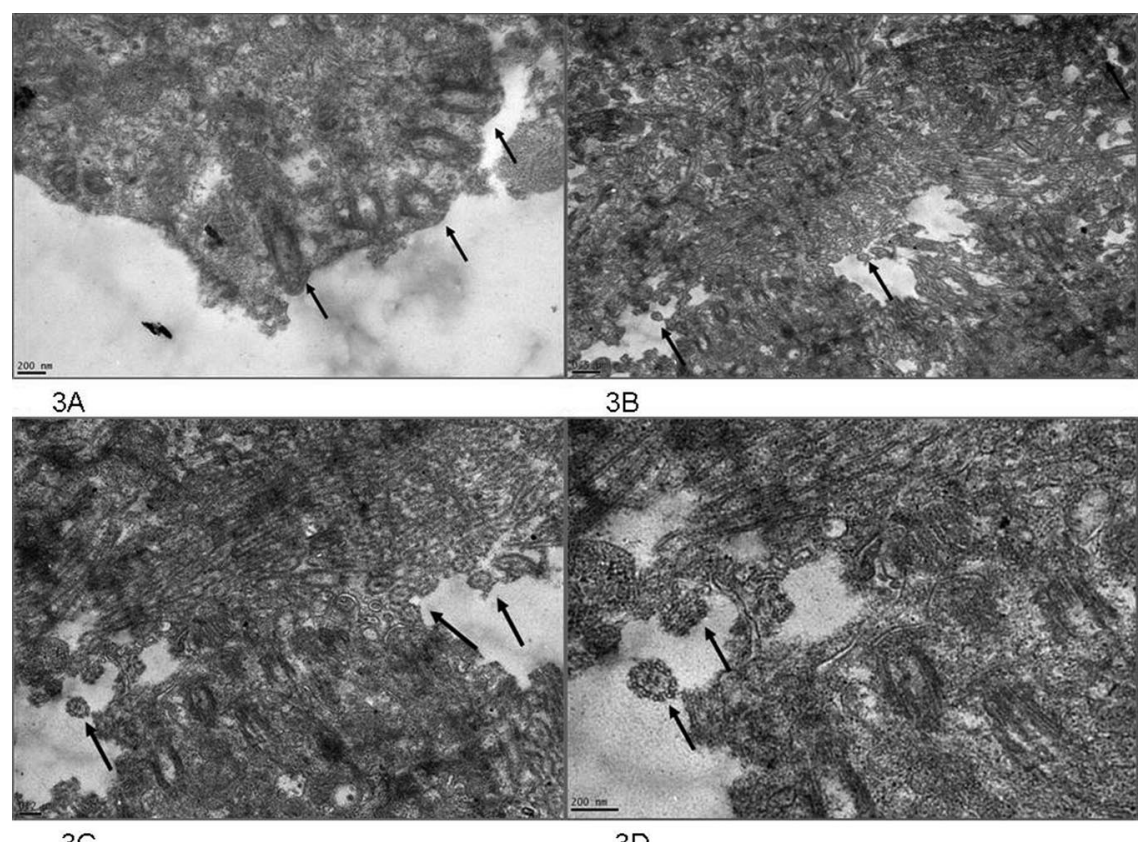

$3 \mathrm{C}$

$3 \mathrm{D}$

Fig. 3. Electron microscopy of bronchial mucosa biopsy. Axonem structures were not preserved in all specimens (A). The ciliary extensions were not seen in most of the epithelial cells (black arrows). C is a magnification of $\mathrm{B}$. All but some cilia and axoneme structures were decayed, but peripheral microtubules had normal structure (black arrows in B, C, and D).
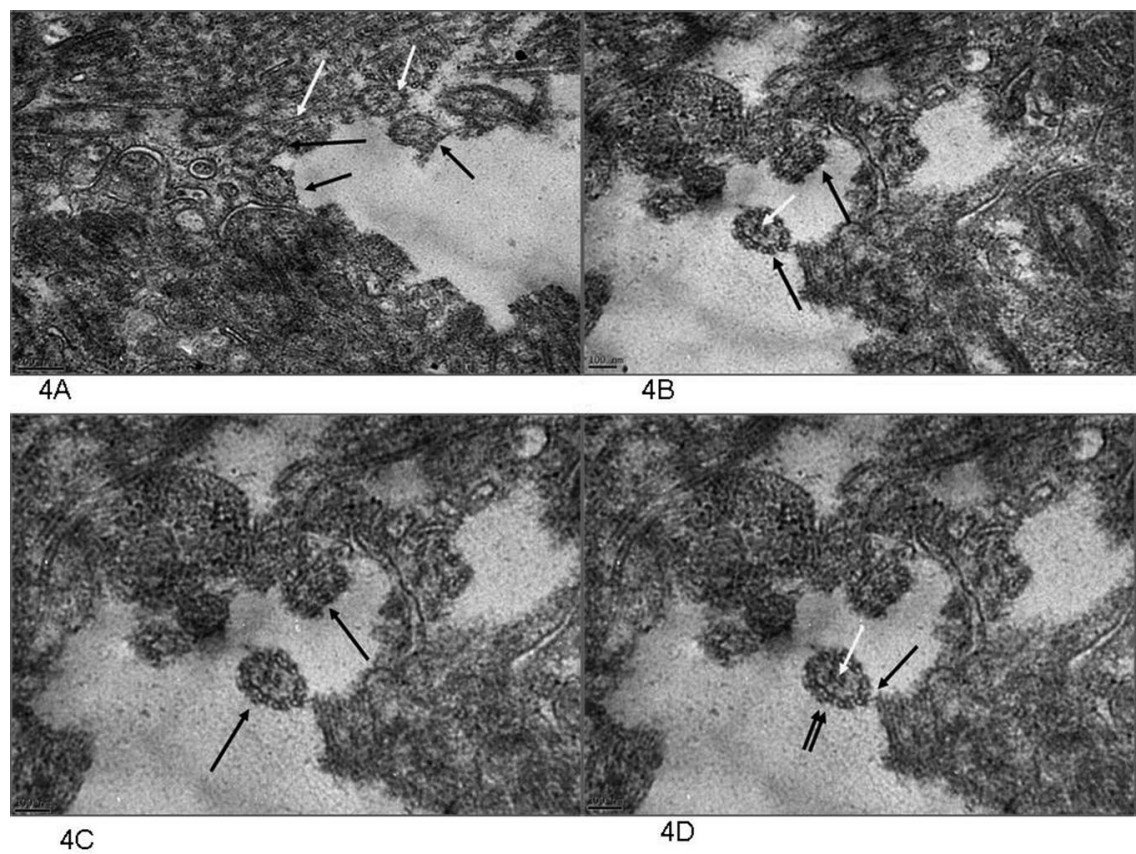

Fig. 4. Electron microscopy of bronchial mucosa biopsy. The outer dynein arms at the outer parts of the peripheral microtubules were not seen in 9 doublet microtubules. The black arrows point to 9 doublet microtubules. In $A$ and $B$ the white arrows point to 2 free central microtubules. $\mathrm{C}$ is a magnification of $\mathrm{B}$. In some axonemes, nexin links were observed in the inner part of the peripheral doublet microtubules. The 2 free central microtubules were seen in some cilia. In $D$ the doubled black arrows point to the nexin link, the black arrow points to dynein arms, and the white arrow points to the central pair of microtubules.

from the inferior or middle turbinate using a sterile cytology brush may be studied for ciliary beat pattern and frequency using digital high-speed video imaging, where dys- kinetic cilia lack the classical sideways recovery sweep. Abnormalities in ciliary beat have been correlated to ultrastructural defects, and normal ciliary motion essentially 
excludes PCD. ${ }^{9,10}$ The absence of pathognomonic clinical and laboratory signs makes PCD difficult to diagnose. Definitive diagnosis relies on a combination of clinical evaluation and electron microscopic analysis of the ultrastructure of the cilia of the bronchial wall or nasal biopsy specimens. ${ }^{11}$ The axoneme of motile cilia is composed of 9 peripheral doublet microtubules, with attached outer and inner dynein arms and radial spokes surrounding a central complex, with 2 central microtubules and the central sheath. Cilia consist of over 250 proteins, making a broad spectrum of defects possible. Currently 3 genes (DNAI1, DNAH5, and DNAH11) that encode for dynein proteins (axonemal and cytoplasmic) have been linked to recessive PCD. ${ }^{12,13}$

In our patient bronchial biopsy samples were examined under electron microscope. A completely preserved axoneme structure was not observed in every field. Basal body was observed in cytoplasm of many epithelial cells; however, some had no ciliary extensions (see Fig. 3A). In cross sections, despite the fact that all cilia and axoneme were not completely preserved in structures in which ciliary extension was observed (see Figs. 3B, 3C, and 3D), peripheral microtubules had almost normal structure (see Figs. 3D, 4A, and 4B). Dynein arms at the external side of the peripheral microtubules were not observed in some of 9 doublet microtubules (see Fig. 4A, 4B, 4C, and 4D). On the other hand, some axonemes exhibited structures at the inner side of the peripheral doublet microtubules, which were considered to be nexin links (see Fig. 4D). Two central free microtubules were observed in some cilia (see Fig. 4D), while one of the microtubules was intact and the other was unpreserved in some cilia.

PCD diagnostic criteria on electron microscopy consist mainly of 3 ciliary defects. The main ultrastructural defect can concern the outer dynein arm (total absence or short outer dynein arm isolated or associated with absence of inner dynein arm), the inner dynein arm (absence of inner dynein arm isolated or associated with radial spoke defect), or central complex abnormalities (central microtubules absent or single). ${ }^{14}$ The defect pattern is similar in children and adults, involving dynein arms (81.2\%) or central complex $(18.8 \%)$. Central microtubule defect is rare, and combined central microtubule defect and dynein defect is even rarer. Situs inversus has not been observed in PCD patients with central complex defect. ${ }^{15}$ In our patient the outer dynein arms were absent and the central microtubule was single, confirming the diagnosis of PCD. Positive saccharin test, her parents' consanguinity, her sister's history of bronchiectasis, her history of middle lobectomy for bronchiectasis, and her infertility contributed to the diagnosis.

The principal treatment during exacerbation includes daily aggressive chest physiotherapy, antibiotics, expectorants, and supportive pulmonary care. Surgical interven- tion for bronchiectasis is rarely recommended, but can be beneficial when the disease is localized. Prognosis can be poor in those who fail to respond to conservative management. In severe cases, bilateral lung transplantation should be considered. ${ }^{16,17}$

PCD should be considered in a patient with bilateral bronchiectasis, frequent pulmonary infections, infertility, a history of pulmonary resection, and/or parental consanguinity. Biopsy must be obtained and examined via transmission electron microscopy for definite diagnosis.

\section{Teaching Points}

- In patients with lower-respiratory-tract infections, transmission electron microscopy is a feasible and very useful method for definitive diagnosis of PCD.

- Recurrent lower-respiratory-tract infections, bronchiectasis, and infertility are the most important clinical features of PCD.

- The mode of genetic transmission in PCD is unclear, but autosomal recessive transmission is likely.

- The absence of situs inversus does not exclude the diagnosis of PCD.

- Surgery can be an option if the bronchiectasis is localized and complications develop.

- Early diagnosis, treatment with antibiotics, and pulmonary rehabilitation improve survival.

\section{REFERENCES}

1. Barker AF, Ahmed SY. Bronchiectasis. In: Fishman AP, Elias JA, Grippi MA, Senior RM, Pack AI, editors. Fishman's pulmonary diseases and disorders, volume 2. London: McGraw-Hill; 2008: 2183-2193.

2. Iseman MD, Chan ED. Bronchiectasis. In: Mason RJ, Broaddus VC, Martin TR, King TE, Schraufnagel DE, Murray JF, Nadel JA, editors. Murray and Nadel's textbook of respiratory medicine, 5th edition. Volume 1. Philadelphia: Saunders/Elsevier; 2010:1029-1030.

3. Akil I, Kavukçu S, Inan S, Yilmaz O, Atilla P, Islekel H, et al. Evaluation of histologica changes in the urinary tract of hypercalciuric rats. Pediatr Nephrol 2006;2(11):1681-1689.

4. Bi J, Bai C, Qiao R. A 27-year-old Chinese man with recurrent respiratory infections. Chest 2010;137(4):990-993.

5. Corkey CW, Levison H, Turner JA. The immotile cilia syndrome. A longitidunal survey. Am Rev Respir Dis 1981;124(5):544-548.

6. Santamaria F, Montella S, Tiddens HA, Guidi G, Casotti V, Maglione M, Jong PA. Structural and functional lung disease in primary ciliary dyskinesia. Chest 2008;134(2):351-357.

7. Skeik N, Jabr FI. Kartagener syndrome. Int J Gen Med 2011;4: 41-43.

8. Theegarten D, Ebsen M. Ultrastructural pathology of primary ciliary dyskinesia: report about 125 cases in Germany. Diagn Pathol 2011; 24(6): 115 . 


\section{Primary CiLIARY DysKinESIA}

9. Stannard WA, Chilvers MA, Rutman AR, Williams CD, O'Callaghan C. Am J Respir Crit Care Med 2010;15;181(4):307-314.

10. Chilvers MA, Rutman A, O'Callaghan C. Ciliary beat pattern is associated with specific ultrastructural defects in primary ciliary dyskinesia. J Allergy Clin Immunol 2003;112(3):518-524.

11. Shoemark A, Dixon M, Corrin B, Dewar A. Twenty-year review of quantitative transmission electron microscopy for the diagnosis of primary ciliary dyskinesia. J Clin Pathol 2012;65(3):267-271.

12. Diakow J, Svobodova T, Hrach K, Cinek O, Pohunek P. Effectiveness of sequencing selected exons of DNAH5 and DNAI1 in diagnosis of primary ciliary dyskinesia. Pediatr Pulmonol 2012;47(9):864-875.

13. Leigh MW, O'Callaghan C, Knowles MR. The challenges of diagnosing primary ciliary dyskinesia. Proc Am Thorac Soc 2011;8(5): 434-437.
14. Papon JF, Coste A, Roudot-Thoraval F, Boucherat M, Roger G, Tamelat A, et al. A 20 year experience of electron microscopy in the diagnosis of primary ciliary dyskinesia. Eur Respir J 2010;35(5): 1057-1063.

15. Sturgess JM, Chao J, Wong J, Aspin N, Turner JA. Cilia with defective radial spokes: a cause of human respiratory disease. N Engl J Med 1979;300(2):53-56.

16. Bush A, Chodhari R, Collins N, Copeland F, Hall P, Harcourt J, et al. Primary ciliary dyskinesia: current state of the art. Arch Dis Child 2007;92(12):1136-1140.

17. Barbato A, Frischer T, Kuehni CE, Snijders D, Azevedo I, Baktai G, et al. Primary ciliary dyskinesia: a consensus statement on diagnostic and treatment approaches in children. Eur Respir J 2009; 34(6):1264-1276. 